\title{
FPGA Kullanılarak Görüntülerin Gerçek Zamanlı Olarak OTSU Metodu ile Bölütlenmesi*
}

\author{
Halil Kaygısız ${ }^{1 \dagger}$, Abdülkadir Çakır ${ }^{2}$ \\ ${ }^{\mathbf{1} A k d e n i z ~ U ̈ n i v e r s i t e s i, ~ K o r k u t e l i ~ M Y O, ~ B i l g i s a y a r ~ P r o g r a m c ı l ı ̆ ̆ ı ~ B o ̈ l u ̈ m u ̈, ~ A n t a l y a, ~ T u ̈ r k i y e ~(O R C I D: ~ 0000-0002-5685-4799) ~}$ \\ ${ }^{2}$ Teknoloji Fakültesi Elektrik ve Elektronik Mühendisliği Bölümü, Süleyman Demirel Üniversitesi, Isparta, Türkiye \\ (ORCID: 0000-00002-2902-9996)
}

(İlk Geliş Tarihi 30 Ocak 2020 ve Kabul Tarihi 31 Mart 2020)

(DOI: 10.31590/ejosat.682278)

ATIF/REFERENCE: Kaygısız, H. \& Çakır, A. (2020). FPGA Kullanılarak Görüntülerin Gerçek Zamanlı Olarak OTSU Metodu ile Bölütlenmesi. Avrupa Bilim ve Teknoloji Dergisi, (18), 911-917.

Öz

OTSU, gri seviye görüntülerin bölütlenebilmesinde kullanılabilen bir eşik tespit metodudur. Görüntünün başarılı bir şekilde bölütlenmesinde eşik değeri büyük önem taşımaktadır. Eşik değerinin çok büyük seçilmesi ile oluşturulacak yeni görüntüde yanlışlıkla pikselerin birçoğu beyaz, küçük seçilmesi durumunda ise siyah olacaktır ve görüntüde saklanan veri azalacaktır. Belki de aranan bilgi kaçırılacaktır. Ayrıca OTSU metodunda, ortamdaki 1şık değişimlerinden bölütleme sonucunun en az şekilde etkilenmesini sağlayacak eşik değeri otomatik olarak hesaplanmaktadır. OTSU metodunun gerçek zamanlı olarak görüntüye uygulanabilmesinde işlem yükünün çok fazla olmasından dolayı yüksek kapasiteli ve maliyetli donanımlara ihtiyaç duyulmaktadır. Bu çalışmada yüksek işlem kapasitesine sahip olması ve düşük maliyeti olması sebebiyle FPGA kullanılmıştır.

\section{Real Time Image Segmentation Using FPGA with OTSU Method}

\begin{abstract}
OTSU is a threshold value calculation method, which use to segmentation of grayscale images. Threshold value is very important for successful segmentation of the images. If you mistakenly select big threshold value, many pixels in the new image will be white or If you select small threshold value, a lot of pixels in the new image will be black and data stored in the image will be reduced. Maybe the requested data will be lost. In addition, the threshold value is calculated automatically with OTSU method ensuring that the segmentation result is minimally affected from change in ambient light. Because the OTSU method can be applied to the image in real time, high capacity and costly equipment are required due to the high processing load.This study was used in the FPGA due to its low cost and having high processing capacity.
\end{abstract}

Keywords: FPGA, OTSU Method, Image Segmentation, Real-Time System

\footnotetext{
* Bu çalışma daha önce düzenlenen Uluslararası Bilgisayar Bilimleri ve Mühendisliği Konferansı'nda tam metin bildiri olarak sunulmuştur. $\dagger$ Sorumlu Yazar:Akdeniz Üniversitesi, Korkuteli MYO, Bilgisayar Programc1lı̆̆1 Bölümü, Antalya, Türkiye, ORCID: 0000-0002-56854799,halilkaygisiz@akdeniz.edu.tr 


\section{Giriş}

Bölütleme; görüntü işleme uygulamalarının önemli bir aşamasıdır. Görüntü içerisindeki bilginin doğru analiz edilmesi uygulamanın sonucunu doğrudan etkilemektedir. Bölütleme işlemi global veya adaptif olarak eşik değerlerinin belirlenmesiyle yapılmaktadır. Adaptif eşik değeri ile yapılan bölütleme ortamdaki ışık değişimlerine göre değişmektedir. Bu yüzden ışık şiddetinin değişimine göre eşik değerinin değişmesi ile bölütlemede başarılı sonuçlar alınmıştır [1]. OTSU olasılık temelli olarak çalışan görüntü işleme uygulamalarında sıkça kullanılan bir algoritmadır. Fakat görüntüdeki tüm pikseller için olasılıksal hesaplama yapılması işlem yükünü artırmaktadır. Zamanın çok önemli olduğu gerçek zamanlı uygulamalarda yüksek maliyetli donanımlar kullanılmaktadır. Son yıllarda görüntü işleme çalışmalarında parallel programlama yeteneği, yüksek performansı ve düşük maliyeti ile FPGA kartlar tercih edilmektedir.

Literatür incelendiğinde; Wang ve arkadaşları jpg formatındaki görüntüyü FPGA karta aktarmışlardır ve OTSU metodu ile eşik belirlenerek görüntünün bölütlenmesini sağlamışlardır [2]. Ieno ve arkadaşları; simulink programını kullanarak FPGA karta aktardıkları görüntüyü görüntü işleme arabirimini kullanarak hazır OTSU aracı ile eşik değerini tespit etmişlerdir [9]. Literatürdeki çalışmalarda görüntüler kameralar aracılı̆̆ ile FPGA karta aktarılmamaktadır. Görüntüler genellikle jpg formatında veya matris olarak FPGA karta aktarılmıştır. Bu çalışma ile kameradan alınan gerçek zamanlı görüntülerin FPGA kullanılarak alınması ve gerçek zamanlı olarak bölütlenmesi gerçekleştirilmiştir.

\section{Materyal ve Metot}

\subsection{FPGA}

FPGA, "Sahada Programlanabilir Kapı Dizileri” anlamındaki "Field Programmable Gate Array" ifadesinin kısaltılmış şeklidir. FPGA'in yapısı GateArrayASIC'lere benzer bu nedenle kapı dizileri ismi verilmiştir.

FPGA, üretimi yapıldıktan sonra istenilen fonksiyonlara göre kullanıcı tarafından donanım yapısı tekrar tekrar değiştirilebilen tümleşik devre olarak tanımlanabilir. Kullanıcının uyguladığı probleme göre, içerisindeki mantık kapıları birbirlerine bağlanarak istenilen yapı gerçeklenebilir [3].

FPGA paralel işlem yeteneğinden dolayı işlem yükü fazla olan işlemlerde tercih edilmektedir. Görüntü işleme ve örüntü tanıma alanlarında yapılan işlemlerin işlem yükünün fazla olmasından dolayı bu çalışma alanlarında FPGA'lar sıkça kullanılmaktadır [4].

Gerçek zamanlı görü uygulamalarında işlem yükünün fazla olmasına karşın hızlı sonuç üretilmek zorundadır. OTSU metodunun çalışma yapısı ve matematiksel işlem yükü göz önünde bulundurulduğunda FPGA kullanımı gerekli donanım maliyetini düşürerek başarılı sonuçlar alınmasını sağlamıştır [5].

Çalışmada Altera firmasııın DE2i-115 FPGA kartı ve D5M CMOS mozaik kamerası kullanılmıştır.

\subsection{OTSU METODU}

Eşikleme; gri seviye görüntülerinin ikili görüntülere dönüştürülme işlemidir. Eşikleme işlemi belirlenen eşik değerinin altındaki piksellerin siyaha, üstündeki piksellerin ise beyaza dönüştürülmesidir.

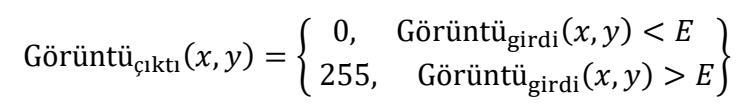

Denklem (1)'deki 'E' değeri eşik değerini ifade etmektedir. Eşik değeri tek bir görüntü için deneme yanılma yöntemi ile tespit edilebilirken farklı 1şık ortamında başarılı sonuç alınamayacaktır. Bu nedenle eşik değeri ortamdaki 1şık seviyesine göre değişiklik göstermelidir. NobuyukiOtsu'nun 1979'da geliştirdiği OTSU metodu her görüntü için farklı eşik değerinin hesaplanmasını sağlamaktadır. Bu metod ile görüntü üzerindeki pikseller arka plan ve bölütlenmek istenen alan olmak üzere 2 farklı sınıfa ayrılmaktadır. Sınıflara ayırma işlemi gerçekleştirilirken herbir eşik değeri için ayrı ayrı sınıf içi veya sınıf arası varyans değeri hesaplanır. Sınıf içi varyans değeri en küçük olan değer, en uygun eşik değerini belirtmektedir. Bu değer aynı zamanda sınıflar arasındaki en büyük varyans değeridir. Sınıflar arası varyans değerinin hesaplanması daha az işlem gerektirmektedir. Varyans hesaplama işlemi ise histogram dizisi üzerinden yapılmaktadır. Varyans; histogram dizisinin tüm elemanlarının dizinin ortalamasına olan uzaklıklarının karelerinin ortalaması ile hesaplanmaktadır. Bu değer incelenerek histogram dizisindeki her bir değerin ortalamaya olan uzaklığı görülebilir [2]. Denklem (2)'de N elemanlı bir histogram dizisi için varyans hesaplama formülü verilmiştir.

$$
\sigma^{2}=\sum_{i=0}^{N-1}\left(x_{i}-x_{i}^{\prime}\right) P\left\{x_{i}\right\}
$$


Denklem (2)'deki x'i ifadesi ağırlıklı ortalamayı, $\mathrm{P}\{\mathrm{xi}\}$ ise olasılık fonksiyonunu ifade etmektedir. MxN boyutundaki bir görüntünün histogram dizisi için i tonunun gelme olasılığı histogram değerinin toplam piksel sayısına bölünmesiyle bulunmaktadır.

$$
\begin{gathered}
\sigma_{\text {siyah }}=\sigma-\sigma_{\text {beyaz }}(3) \\
=s y_{s}(t) s y_{b}(t)\left(a s o_{s}(t)-a s o_{b}(t)\right)
\end{gathered}
$$

Siyah ve beyaz sınıfları arası varyans değeri Denklem (3) ile bulunmaktadır [2].

Denklem (3)'deki sy değişkenleri sınıf yoğunluklarını, aso değişkenleri ise ağırlıklı sınıf ortalamalarını ifade etmektedir. Sınıf yoğunlukları ve ağırlıklı sınıf ortalamaları Denklem (4) ile hesaplanmaktadır.

$$
\begin{aligned}
s y_{s}(t) & =\sum_{i=0}^{t} P\{i\}, \quad s y_{b}(t)=\sum_{i=t+1}^{255} P\{i\} \\
& \operatorname{sso}_{s}(t)=\sum_{i=0}^{t} P\{i\} R_{i}, \quad s y_{b}(t)=\sum_{i=t+1}^{255} P\{i\} R_{i}
\end{aligned}
$$

Denklem (4)'deki Ri değeri i. renk seviyesini ifade etmektedir. Deklemler ile 0 ile 255 arasındaki herbir değer için sınıflar arası varyans değeri hesaplanmakta ve en büyük varyansa sahip t değeri ise E eşik değeri olarak belirlenmektedir [7].

\section{Araștırma Sonuçları ve Tartıșma}

\subsection{FPGA Kullanılarak Gerçek Zamanlı Olarak Görüntülerin Alınması}

Görüntü almak için Altera firmasını FPGA kartları için ürettiği D5M mozaik kamerası kullanılmıştır. Kamera maksimum 5 megapilsellik çözünürlükte 15fps ile görüntü verebilmektedir. Çözünürlük 640x480 e kadar düşürülerek 70fps görüntü alınabilmektedir. Mozaik kameraların özelliği her bir pikselde R,G ve B değerlerinden yalnızca biri saklanmaktadır. Her pikseldeki RGB değeri interpolasyon yöntemiyle hesaplanmaktadır [6].

Kameradan görüntü alma aşamaları Şekil 1'de verilmiştir.

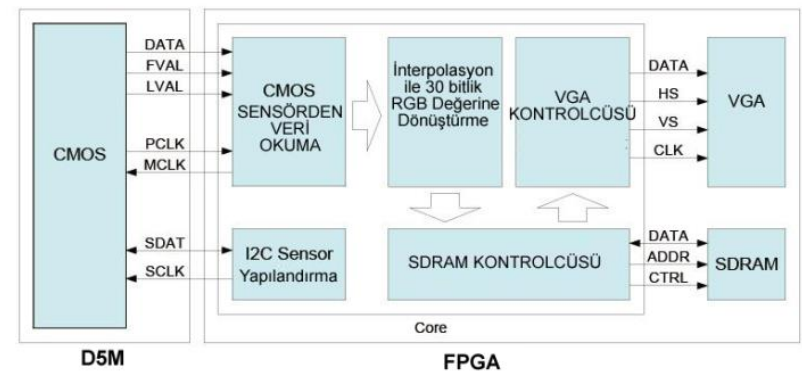

Şekil 1. CMOS sensörden veri alma aşamaları [8]

RAW formatında alınan görüntü interpolasyonla RGB'ye dönüştürüldükten sonra SDRAM'a yazılmaktadır. FPGA kartta bulunan SDRAM'a veriler 16 bit uzunluğunda yazılmaktadır. Her piksel için 30 bitlik bir RGB değeri tutulduğu düşünüldüğünde bir piksel için RGB değeri 2x16bit ile SDRAM'a kaydedilebilmektedir. 640x480 çözünürlüğünde bir görüntü hafizada 1200 kb yer kaplamaktadır. SDRAM'a yazılan adreslerden veriler okunup işlenerek VGA kontrolcüsüne gönderilmektedir. VGA kontrolcüsü gelen verileri monitöre göndermektedir. CMOS sensörden alınan veriler herhangi bir zamanda kayıp yaşanmadan gerçek zamanlı olarak SDRAM'den okunarak işlenmekte ve monitöre aktarılabilmektedir.

\subsection{OTSU Metodu İle Gerçek Zamanlı Olarak Görüntülerin Bölütlenmesi}

Altera firmasının ürettiği DE2i-115 FPGA kartı üzerinde yazılım geliştirmek için Verilog programlama dili ve yine Altera firmasının sunduğu QuartusFPGA Tasarım Yazılımı kullanılmıştır.

FPGA'de geliştirilen uygulamada oluşturulan modüller ve veri iletişimi Şekil 2'de gösterilmiştir. 


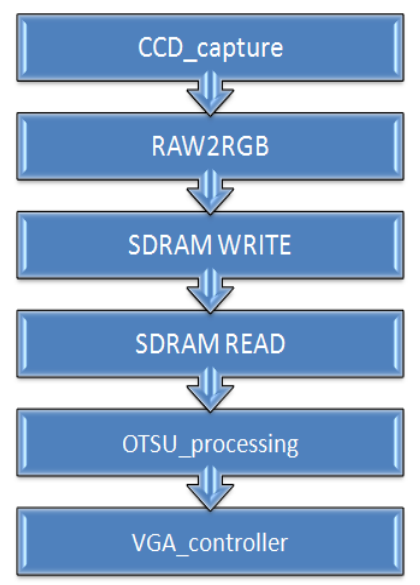

Şekil 2. Yazılımda oluşturulan modüller

CCD_capture: CMOS kameradan görüntülerin alındığı işlem modülüdür. Ana görevi GPIO portuna bağlı kameradan piksel piksel verileri okumak ve verinin yatayda ve dikeyde sayaçlar vasıtasıyla görüntüdeki konumunun kaydını tutmaktır. Bu modülde alınan veri; sensör üzerine düşen görüntünün dijital işlemci tarafından işlenmemiş ham halini oluşturmaktadır.

RAW2RGB: Görüntünün işlenebilmesi için anlamlı sayısal verilere dönüştürülmesi gerekmektedir. Bu modüldeCCD_capture modülünden elde edilen ham görüntü RGB formatına dönüştürülmektedir.

SDRAM WRITE: FPGA kartta kullanılan SDRAM 16 bitlik bloklar halinde kullanılmaktadır. Bu modülde 30 bit uzunluğunda olan RGB değeri 2 adet 16 bitlik SDRAM bloğuna yazılmaktadır. "G" değeri ikiye bölünerek 5'er bit olarak her iki bloğa "R" ve "B" değerlerinin yanına yazılmaktadır. Bu yöntemle SDRAM daha etkin kullanılmıştır.

SDRAM READ: SDRAM'a yazılan RGB değerlerinin okunduğu modüldür

OTSU_processing: OTSU metodunun FPGA üzerinde uygulandığı modüldür. Öncelikle görüntü SDRAM'a piksek piksel kaydedilirken aynı anda okunarak pikseller Denklem 5'den faydalanarak gri tona dönüştürülmektedir.

$$
\text { Gray }=0.299 * \mathrm{R}+0.587 * \mathrm{G}+0.114 * \mathrm{~B}
$$

Görüntü piksel piksel okunup aynı anda işlendiği için görüntünün tamamı hafızaya kaydedildiğinde histogramı da çıarılmış olmaktadır. Histogram çıkarıldıktan sonra eşik değerinin hesaplanması işlemleri yapılmakta ve görüntü eşiklenerek monitöre aktarılmaktadır (Şekil 3).

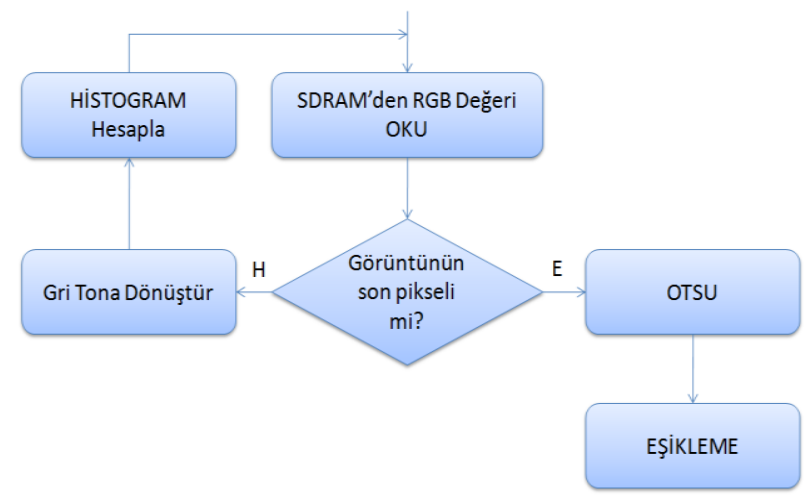

Şekil 3. OTSU_processing modülünün çalışma algoritması

OTSU eşik değerinin hesaplanması için en önemli aşamayı oluşturan histogram dizisinin oluşturulmasıdır. Histogram; görüntüdeki renk değerlerinin sayısını gösteren dizidir. Görüntüdeki her bir renk düzeyinden kaç tane olduğunun bulunmasıyla görüntünün histogramı çıkarılmaktadır (Şekil 4). 


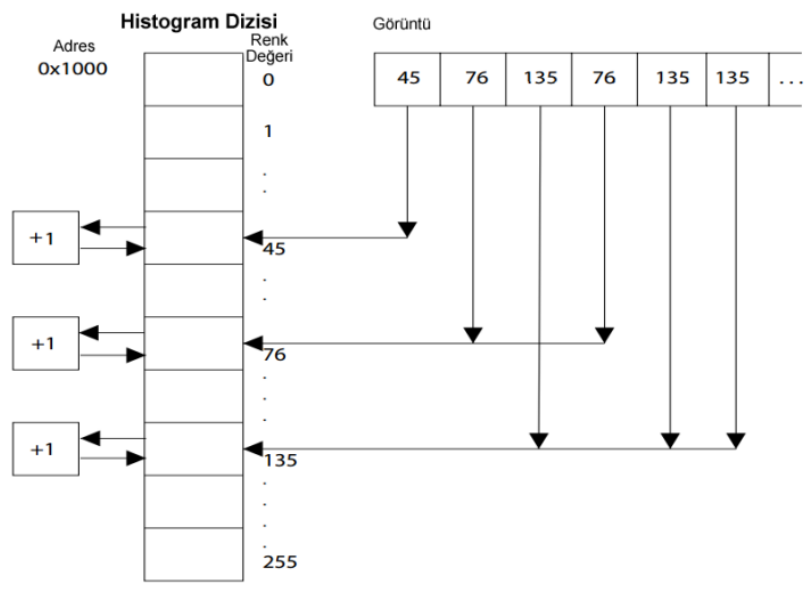

Şekil 4. Histogram çıkarma işlemi [5]

Histogram dizisi oluşturulduktan sonra histogram dizisindeki her piksel için varyans hesaplanmaktadır. Daha sonra sınıflar arası varyans değerinin hesaplanabilmesi için her iki sınıf içinde sınıf yoğunlukları ve ağırlıklı sınıf ortalamaları hesaplanmaktadır. Histogram dizisindeki değerlerden en büyük varyans değerine sahip olan değer eşik değeri olarak belirlenmektedir. Görüntüdeki pikseller SDRAM'dan yeniden okunarak eşikleme yapılmakta ve monitöre aktarılmak üzere vga_controllermodülüne gönderilmektedir.

VGA_controller: Kameradan gelen görüntünün monitöre aktarıldığı modüldür. Gelen pikselin x ve y koordinatlarındaki konumu hesaplanmaktadır. VGA_controllermodülü ile monitöre görüntünün piksel değeri aktarıldıktan sonra yeni görüntü piksel değeri SDRAM'a kaydedilmektedir (Şekil 5).

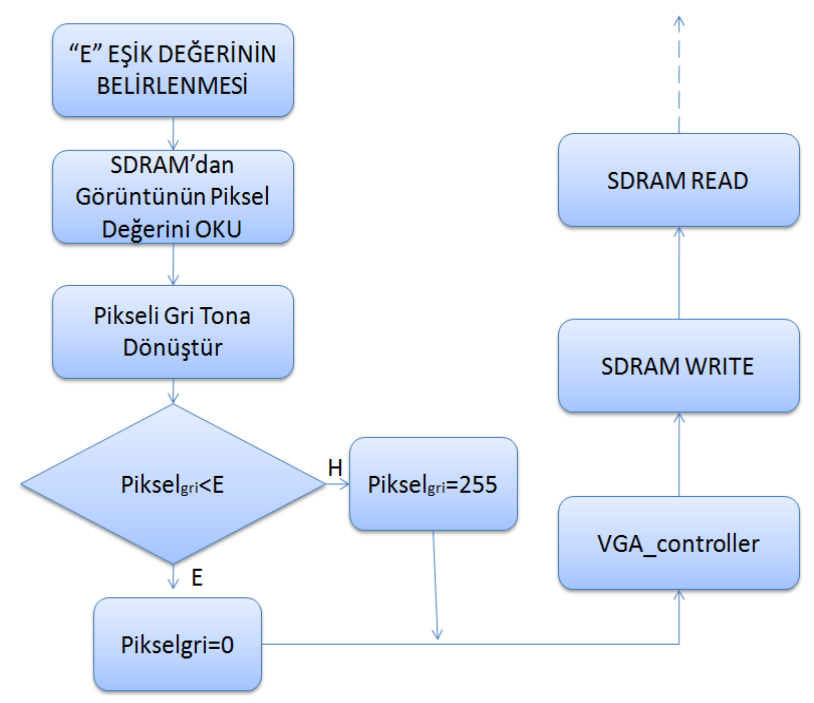

Şekil 5. Görüntünün bölütlenmesi

VGA_controller modülü SDRAM WRITE modülünün tetikleyeni olduğu için iki modül paralel çalı̧maktadır. Böylelikle monitöre piksel aktarıldıktan sonra yeni görüntünün piksel değeri alınmaktadır.

\section{Sonuç}

Çalışma ile görüntünün bölütlenmesi için belirlenmiş en iyi global eşik değeri ile OTSU metodu ile belirlenmiş eşik değeri karşılaş̧ırılmıştır. Şekil 6'da sistem görüntüsü ve Şekil 7'de de alınan orijinal görüntü yer almaktadır. Şekil 8 (a), (c) ve (e)'de global eşik değeri ile farklı ş̧ık düzeylerindeki bölütleme sonuçları görülmektedir. Şekil 8 (b), (d) ve (f)'de ise OTSU metodu kullanılarak bölütlenmiş görüntüler gösterilmektedir. 


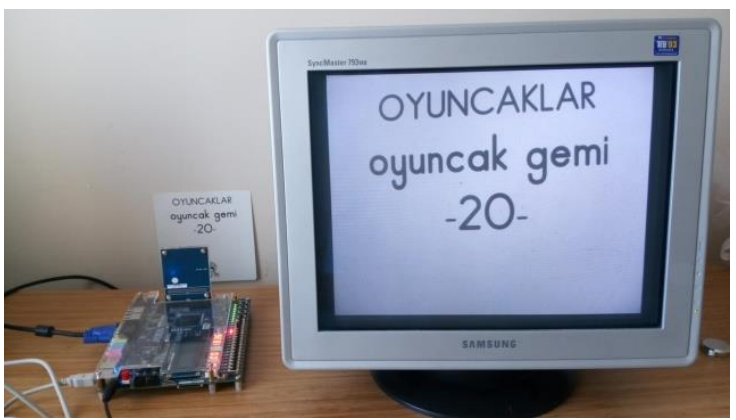

Şekil 6. Sistemin görüntüsü

\section{OYUNCAKLAR \\ oyuncak gemi -20 -}

Şekil 7. Orijinal görüntü

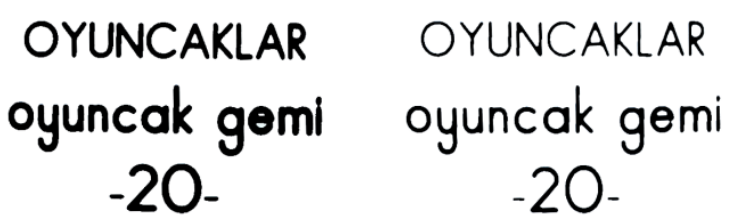

(a)

(b)

OYUNCAKLAR OYUNCAKLAR

oyuncak gemi oyuncak gemi

-20- $\quad 20$ -

(c)

(d)

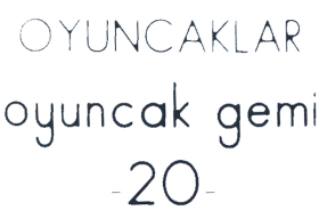

(e)
OYUNCAKLAR

oyuncak gemi -20 .

Şekil 8. Global eşik değeri (a) Düşük 1şık, (c) Uygun 1şık, (e) Yüksek 1şık OTSU eşik değeri (b) Düşük 1şık, (d) Uygun 1şık, (f) Yüksek 1şık 
Görüntüler karşılaştırıldığında OTSU metodunun başarılı sonuçlar verdiği görülmektedir. Global eşik değeri 85 olarak belirlenmiştir. Uygun ışıkta Global eşikleme ile OTSU metodunun başarımları benzer düzeyde olduğu görülmektedir. Fakat 1şık düzeyindeki değişim sebebiyle global eşikleme sonucu olumsuz yönde değişmektedir. Global eşik değerinde düşük ve yüksek 1şıkta bölütlenmesi gereken bölgede veri kaybı yaşanmaktadır. OTSU metodunda eşik değeri düşük 1şıkta 79, uygun ışıkta 86 ve yüksek ışıkta 95 olarak hesaplanarak otomatik olarak bölütleme yapılmıştır. Şekil 8.a incelendiğinde global eşik değeri olması gerektiğinde daha büyük bir değer olduğu için daha fazla piksel görüntü de yer almaktadır. Şekil 8.e'de ise global eşik değeri olması gerektiğinde daha küçük bir değer olduğu için daha az piksel görüntü de yer almaktadır. Saniyede 30 kare görüntü alındığı göz önünde bulundurulduğunda her görüntü karesi için OTSU eşik değeri ayrı ayrı hesaplanmaktadır. 50 mhz frekansında çalışan DE2i-115 FPGA kartında OTSU metodu 19.040ns de sonuç üretmektedir. FPGA üzerinde gerçekleştirilen çalışma ile görüntü kameradan gerçek zamanlı olarak alınmaktadır. FPGA kullanılarak kameradan alınan görüntü üzerinde OTSU algoritması başarılı bir şekilde çalıştırılmıştır Tablo 1'de FPGA üzerinde geliştirilen uygulama yazılımının ihtiyaç duyduğu donanım verileri gösterilmektedir.

Çalışma ile gerçek zamanlı olarak kameradan alınan görüntü FPGA kullanılarak OTSU algoritması çalıştırılmıştır. Global eşik değeri ile OTSU eşik değeri ile yapılan bölütleme sonuçları karşılaş̧ırılmıştır. Çalışma ile programlama yapısındaki zorluktan dolayı kısıtlı çalışmanın olduğu FPGA temelli programlama çalışmalarına katkı sağlanmıştır.

Tablo 1. FPGA uygulama özeti

\begin{tabular}{|l|l|}
\hline AÇIKLAMA & DEĞER \\
\hline FPGA Kart Modeli & DE2i-115 \\
\hline FPGA Modeli ve Lojik Eleman Say1s1 & EP4CE115F29C7 \\
& 114.480 \\
\hline Toplam Lojik Eleman Sayıs1 & 4.016 \\
\hline Toplam Kaydedici Sayı1 & 2117 \\
\hline Kullanılan Toplam Pin Sayıs1 & 428 \\
\hline Toplam PLL Sayıs1 & 1 \\
\hline
\end{tabular}

\section{Kaynakça}

[1] Seow M. J. andAsari K. V, "A parallel VLSI architectureforreal-time segmentation of imageswithcomplexbackgroundenvironment," Proc. 10th NASA Sym. on VLSI Design, Albuquerque, New Mexico, USA, 2002, pp. 1031-1036.

[2] Wang J., Yang C., Zhu M., Wang C., "Implementation of Otsu'sThresholdingProcessBased on FPGA", ICIEA, 479-483, 2009.

[3] Bochem A., Kent K. B., Herpers R., "FPGA based Real-Time Object DetectionApproachwithValidation of Precision andPerformance", 22nd IEEE International Symposium on RapidSystemPrototyping, 9-15, 2011.

[4] Ozsarac I. and Ulusoy I., "Tam Arama Video Sabitleme Yönteminin Gerçek Zamanlı FPGA Uygulaması", 20th SignalProcessing And Communications Applications Conference (SIU), 1-4, 2012.

[5] Ladgaonkar A.,Balsundar P., Konde V. andRaj A. N., "FPGA BasedImplementation of RatioHistogram", International Journal of Advances in Engineering\&Technology, 747-752, 2015.

[6] Xia H.,Key S., Su X., Liu P., Liu B., "A design of mosaicline-scancamerabased on FPGA”, Computerand Information Science (ICIS), $455-458,2014$.

[7] Vala H. J. andBaxi A., "A Review on Otsu Image SegmentationAlgorithm", International Journal of Advanced Research in ComputerEngineering\&Technology (IJARCET), 387-389, 2013.

[8] Altera, http://www.terasic.com.tw/cgi-bin/page/archive.pl?Language=English\&CategoryNo=68\&No=281\&PartNo=3, TRDBD5M User Manual, 11,07.2016.

[9] Ieno E., Garcés L.M., Cabrera A.J., and Pimenta T.C., "Simple generation of threshold for images binarization on FPGA", Ingeniería e Investigación vol. $35 \mathrm{n} .^{\circ}$ 3, december - 2015 (69-75) 